\title{
Insights into the removal of gaseous oxytetracycline by combined ozone and membrane biofilm reactor
}

\author{
Z.S. Wei ${ }^{\dagger}$, X.L. Chen, Z.S. Huang, H.Y. Jiao, X.L. Xiao \\ School of Environmental Science and Engineering, Sun Yat-sen University, Guangdong Provincial Key Laboratory of Environmental Pollution Control \\ and Remediation Technology, Guangzhou 510006, China
}

\begin{abstract}
Gaseous emerging organic compounds (GEOCs) may harm human health and ecological environment. High temperature composting of livestock manure may produce oxytetracycline (OTC) waste gas. Here, we investigated treatment OTC in waste gas by combined ozone and membrane biofilm reactor (MBfR) with desulphurizing bacteria. The performance, the microbial community, gene function and the mechanism for OTC removal in the ozone-MBfR were evaluated. The ozone-MBfR system could achieve more degradation of OTC completely than MBfR. Desulforibrio, Lentimicrobium, Aminivibrio, Thioalkalispira, Erysipelothrix, Mangroviflexus, Azoarcus, Thauera, Geobacter, Paracoccus, and Dethiosulfatibacter were the dominant genera. Pseudomonas, Escherichia, Bacteroides, Salmonella, Paracoccus, Stappia were contribution to OTC degradation. With the addition of ozone, the community diversity increased; some genera, such as Tenericutes- uncultured, and Desulfovibrio, increased in abundance, whereas others, such as Thauera, and Petrimonas, decreased. Ozone destroyed the enol structure in OTC molecular structure and produces biodegradable products, ozone oxidation was combined with biodegradation, to achieve thoroughly degrade OTC in waste gas. The novel hybrid ozone-MBfR is a cost-effective and robust alternative to GEOCs treatment.
\end{abstract}

Keywords: Bacterial community, Degradation mechanism, Gaseous emerging organic contaminants, OTC in waste gas, Ozone and biological process

\section{Introduction}

Ecological and environmental protection has become a global concern, carbon dioxide emission from conventional fossil fuels contribute to global warming [1], while emerging organic pollutants (EOPs) are serious environmental concerns known for their prominent adverse and hazardous ecological effects, and persistence in nature [2]. Antibiotics, as emerging pharmaceutical pollutants, are widely used as veterinary drugs in livestock breeding. However, these antibiotics cannot be fully absorbed in the animal intestine, and as much as $30-90 \%$ of the maternal compounds will be excreted through feces or urine [3]. The widespread use of tetracycline antibiotics results in the detection of $\mathrm{mg} / \mathrm{kg}$ or even hundreds of $\mathrm{mg} / \mathrm{kg}$ tetracycline residues in animal feces [4]. Antibiotics in animal feces were degraded by high temperature composting $\left(70^{\circ} \mathrm{C}\right)[5]$ During the process of manure composting at high temperature, the high temperature and heap turning made the aerosol containing OTC diffuse into the atmosphere, producing OTC waste gas. Oxytetracycline amendment resulted in a dose-dependent and spe- cies-specific effect on the gut microbiomes and resistomes of two mite species [6]. Antibiotic resistance genes (ARGs) would reduce the efficacy of antibiotic treatment [7]. Gaseous emerging organic compounds (GEOCs) may harm human health and ecological environment because of their toxicity and health risks. Antibiotic resistance gene pollutants were detected in the air of livestock farms, and the stacking of livestock manure would produce sulfur nitrogen odor and emerging organic pollutants [8]. Gaseous emerging pollutants such as brominated flame retardants, phthalates, pharmaceuticals, oxytetracycline (OTC), and personal care products have been detected in indoor air, dust, and pharmacy industry [9]. Phthalate is found in many cosmetics, toys and food packaging, which can interfere with endocrine, reduce sperm number, and seriously lead to testicular cancer. The degradation products of oxytetracycline after composting were still macromolecular substances EOTC $(\mathrm{M} / \mathrm{Z}=461), \alpha$-APO-OTC $(\mathrm{M} / \mathrm{Z}=443)$ and $\beta$ -APo-OTC $(\mathrm{M} / \mathrm{Z}=443)$ [10]. The combination of antibiotics, antibiotic resistance genes (ARGs) and bacteria in compost were released into the atmospheric environment, long-term human ex-
This is an Open Access article distributed under the terms of the Creative Commons Attribution Non-Commercial License (http://creativecommons.org/licenses/by-nc/3.0/) which permits unrestricted non-commercial use, distribution, and reproduction in any medium, provided the original work is properly cited.

Copyright (C) 2022 Korean Society of Environmental Engineers
Received September 26, 2021 Accepted November 28, 2021

${ }^{\dagger}$ Corresponding author

E-mail: weizaishan98@163.com

Tel: +86 2084037096 Fax: +86 2039332690

ORCID: 0000-0002-3325-3368 
posure to this environment would lead to risks of infectious diseases, toxic effects, allergies and cancers [11].

Extensive research and application have been undertaken using advanced oxidation, absorption, electrochemical or biological processes to reduce oxytetracycline emission [12]. The degraded polylactic acid showed around a two times higher OTC adsorption quantity than virgin polylactic acid via biofilm-related alteration of physiochemical properties [13]. Biotechnology is a promising technology for emerging organic contaminants removal using membrane bioreactor, biological filter, biofilm reactor [14]. Membrane bioreactor with nitrifying bacteria degraded OTC [15]. Native bacteria degraded OTC in estuarine sediments [16]. Terminal electron-accepting conditions may influence on the soil microbial community such as nitrate reducing bacteria, sulfate reducing bacteria and degradation of organic contaminants of emerging concern [17]. Trametes versicolor, Ganoderma lucidum, Chlorella sorokiniana could degrade pharmaceuticals of emerging concern in aquatic systems by metabolic biodegradation or in conjunction with other compounds [18]. The succession of the dominated genus from Ca. Kuenenia to Ca. Anammoxoglobus and the positively relationship of parts of ARGs with the dominant bacterium were fulfilled by succession of the potential resistant species induced by ARGs after $\mathrm{Cu}^{2+}$ inhibition [19]. Methanosarcina was contribution to transformation of oxytetracycline, the $\mathrm{FeOn}(\mathrm{OH}) \mathrm{m}$ modified oyster shell powders and enrichment culture could accelerate the transformation of oxytetracycline [20].

Ozone oxidation is also a promising technology for waste gas OTC treatment [21, 22], ozone could react with harmful organic compounds quickly and decompose them, and degrade organic compounds into simpler products [23]. Ozone could fast removal of the antibiotic flumequine from aqueous solution, convert it to low molecular weight carboxylic acids [24]. Effluent organic matter had effect on the removal of emerging contaminants by ozonation [25]. The addition of $\mathrm{MnO}_{2}, \mathrm{H}_{2} \mathrm{O}_{2}$ promoted the transformation of ozone into hydroxyl radical, thus improving the oxidation efficiency of emerging pollutants [26]. But, ozone oxidation may cause secondary pollution during the OTC degradation, bioreactor, its disadvantages, include large volume of bioreactor and slow adaptation to biotoxic TOC in waste gas [27]. Therefore, the combined process of ozone-bioreactor could thoroughly and effectively degrade emerging contaminants of livestock composting waste gas [28]. The combination of ozonation and biological activated carbon filtration could achieve removals of 50\% for dissolved organic carbon and more than $90 \%$ for a wide range of trace organic chemicals [29], almost all drugs and personal care products from treated wastewater could be degraded by biofilter after pre-ozonation [30]. OTC treatment has been widely studied in soil and water, but has received little attention in waste gas. This suggests that coupling of ozonation and membrane biofilm reactor (MBfR) with desulphurizing bacteria for degradation of OTC in waste gas, desulphurizing bacteria may be mutated into OTC degrading bacteria after the supply of gaseous OTC, to realize degrade OTC in waste gas thoroughly.

The objective of this work is to study the degradation of oxytetracycline in waste gas by the integrating reactor of an ozone reactor and a membrane biofilm reactor (MBfR) with desulphurizing bacteria, to reduce biotoxicity, eliminate secondary pollution from ozone oxidation and run stability. The study analysis bacterial community structure and functional genes in MBfR were assessed by $16 \mathrm{~S}$ rDNA sequencing and metagenome sequencing. The intermediate products of oxytetracycline degradation in ozone-MBfR were identified by LC-TOF-MS/MS. The mechanistic for ozone-biological degradation of oxytetracycline were elicited, which is believed to promote the application of the ozone-MBfR.

\section{Materials and Methods}

\subsection{Experimental Procedure}

The experimental setup of the ozone-MBfR integrated reactor for oxytetracycline removal in waste gas was shown in Fig. 1. The integrated reactor included an ozone reactor, a polysulfone hollow

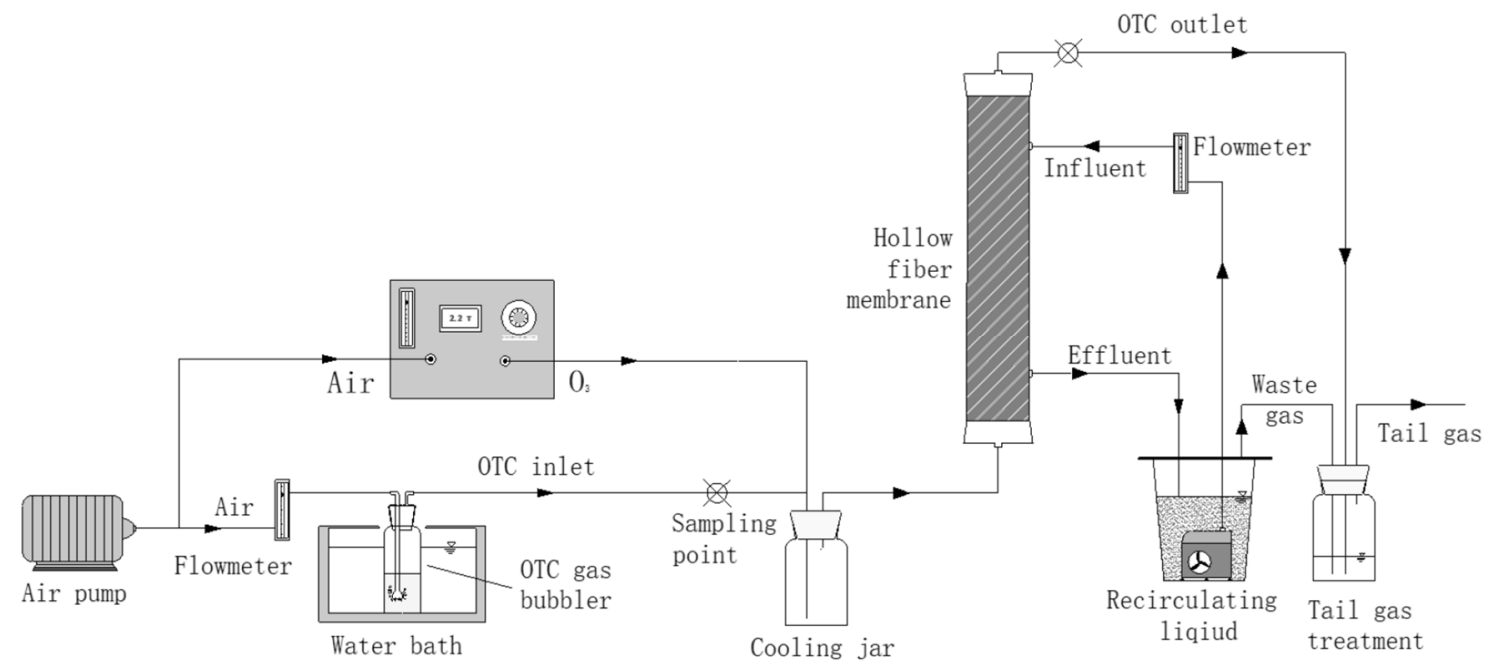

Fig. 1. Schematic diagram of an integrated with an ozone and a membrane biofilm reactor unit for the treatment of waste gases containing oxytetracycline (OTC). 
fiber membrane biofilm reactor, a waste gas mixture (OTC and air) generation system, and a nutrient supply system. The activated sludge from municipal wastewater treatment plant was used to isolate desulphurizing bacteria, which could degrade OTC with the addition of OTC. The microbial nutrient solution containing desulphurizing bacteria was sprayed onto the membrane surface to form biofilm using a subaqueous pump. The recirculating medium was replaced with freshly medium every one week. Ozone with lower concentration is used as the pretreatment to reduce the threat of ozone to the biofilm on the hollow fiber membrane. Therefore, the ozone concentration was selected as 10, 20, 30, 40 and 50 ppm, and the ozone inlet flow rate was $0.15-0.3 \mathrm{~L} \cdot \mathrm{min}^{-1}$.

Batch tests on MBfR or ozone-MBfR, the OTC supplied from the gas cylinders, was first diluted with the compressed air, passed through an air mixture bottle, ozone supplied from the ozone generator; simulated OTC waste gas was flowed upwards through the MBfR, or simulated OTC waste gas first flowed through the ozone reactor and then flowed upwards the bottom of the MBfR. MBfR was operated during $91 \mathrm{~d}$ under the conditions of OTC inlet concentration of $0.05-1.5 \mathrm{mg} \cdot \mathrm{m}^{-3}$, gas residence time (GRT) of $14.5 \mathrm{~s}$, dissolved oxygen (DO), $0.2-1.5 \mathrm{mg} \mathrm{L}^{-1}$; $\mathrm{pH}$ of recirculating medium, 7.6-7.8; spray rate of $30 \mathrm{~mL} \cdot \mathrm{min}^{-1}$ at room temperature. The influence of OTC inlet concentration was investigated from days 1 to 91, OTC inlet concentration, 0-0.5 $\mathrm{mg} \cdot \mathrm{m}^{-3}$ (Phase I, 0-35 d), 0.6-1.0 $\mathrm{mg} \cdot \mathrm{m}^{-3}$ (Phase II, 36-63 d), 1.1-1.5 $\mathrm{mg} \cdot \mathrm{m}^{-3}$ (Phase III, 64-91 d). The $\mathrm{O}_{3}$-MBfR integrated reactor was operated during 50 days under the conditions of OTC inlet concentration of $0 .-1.0 \mathrm{mg} \cdot \mathrm{m}^{-3}$, gas residence time (GRT) of $14.5 \mathrm{~s}$, dissolved oxygen (DO), 0.2-1.5 $\mathrm{mg} \mathrm{L}^{-1}$; $\mathrm{pH}$ of recirculating medium, 7.6-7.8; spray rate of $30 \mathrm{~mL}$. $\min ^{-1}$ at room temperature.

\subsection{S rDNA Sequencing and Metagenomic Sequencing}

Biofilm samples from MBfR were collected to identify and better understand bacterial population compositions and bacterial species which were effective on OTC degradation. The biofilms attached to the membrane surface of MBfR were sampled, assessed by $16 \mathrm{~s}$ rRNA and Metagenomics sequencing, and identify the predominant microorganisms by the procedures of DNA extraction, quantification, purification, polymerase chain reaction (PCR) amplification, cloning and sequencing, gene library construction, Illumina high-throughput sequencing and sequencing data analysis. The metagenome sequencing raw data have been deposited in the NCBI Sequence Read Archive database with the accession number SAMN20079337.

\subsection{Identification of the Intermediate Products of OTC Degradation}

The intermediate products from OTC ozonation, OTC degradation in circulating fluid of MBfR and ozone-MBfR were identified by LC-TOF-MS/MS (Ultimate3000-timsTOF) with Hypersil GOLD C18 column $(1.9 \mu \mathrm{m}, 2.1 \times 100 \mathrm{~mm})$ after liquid extraction. The LC-TOF-MS/MS conditions were as follows: mobile phases were $0.1 \%$ formic acid (A) and acetonitrile (B). For gradient elution, initial 5\% B was increased to $60 \%$ within 2 min and then increased to $100 \%$ in a further $6 \mathrm{~min}$ and keep this condition for $2 \mathrm{~min}$. Finally, the gradient was returned to the initial conditions of $5 \%$
B for 2 min. The injection volume was $3 \mu \mathrm{L}$ and flow rate was $0.3 \mathrm{~mL} \cdot \mathrm{min}^{-1}$ at the column temperature of $40^{\circ} \mathrm{C}$.

\subsection{Analytical Methods}

The OTC concentration was determined by HPLC (Agilent 1260) with a poroshell $120 \mathrm{ES}-\mathrm{C} 18$ column (4.6 × $150 \mathrm{~mm}$ 2.7-Micron) after filtration through a $0.22 \mu \mathrm{m}$ membrane (Syringe) filter. The mobile phase was composed of a mixture of acetonitrile and $0.825 \%$ phosphoric acid water ( $8.25 \mathrm{~mL}$ phosphoric acid $/ 1 \mathrm{~L}$ water), the initial composition was acetonitrile/phosphoric acid water (5/95, $\mathrm{v} / \mathrm{v}$ ), and the gradient was changed to acetonitrile/phosphoric acid water $=40: 60(\mathrm{v} / \mathrm{v})$ over $6 \mathrm{~min}$. Flowrate and injection volume were maintained at $1 \mathrm{~mL} \cdot \mathrm{min}^{-1}$ and $100 \mu \mathrm{L}$, respectively. OTC was detected at $268 \mathrm{~nm}$ by a diode array detector. The retention time for OTC was found to be $3.92 \mathrm{~min}$.

Ozone concentration was measured by an electro-chemical gas analyzer (AIC-800-03, Shenzhen aopul Co. Ltd). Gas flow rates were measured using Model LZB-1 flow meters with units of 0.1 $\mathrm{m}^{3} \cdot \mathrm{h}^{-1}$. The $\mathrm{pH}$ values were measured by a Model $\mathrm{pHB}-3 \mathrm{pH}$ Tester (Sanxin Instrument Company, Shanghai, China). Dissolved oxygen was determined by DO analyzer (YSI Pro20i, Yellow Springs Instrument Inc., USA).

\section{Results and Discussion}

\subsection{Performance of OTC Removal in Waste Gas}

Gaseous oxytetracycline removal performance of the MBfR and ozone-MBfR were shown in Fig. 2. Fig. 2(a) showed the performance of the MBfR with desulphurizing bacteria for OTC removal with the supply of gaseous OTC concentration from 0.05 to $1.5 \mathrm{mg} \cdot \mathrm{m}^{-3}$ during the 91-d continuous running test. With OTC inlet concentration maintained at $0.09 \pm 0.04 \mathrm{mg} \cdot \mathrm{m}^{-3}$ in Phase I from days 1 to 35, OTC removal efficiency increased from 45.5 to $94.1 \%$, $2 \mathrm{~g}$ sodium lactate was added every two days to replenish the carbon source, the microorganisms on the membrane gradually adapted to the oxytetracycline exhaust gas, oxytetracycline removal efficiency gradually increased. In phase II, when OTC concentration was increased to $0.60 \pm 0.08 \mathrm{mg} \cdot \mathrm{m}^{-3}$ at $36 \mathrm{~d}$, OTC removal efficiency fell to $92.1 \%$ at $36^{\text {th }} d$, and then was stabilise at $95.3 \pm 3.2 \%$ from days 37 to 63 . In phase III, when OTC concentration was further increased to $1.33 \pm 0.12 \mathrm{mg} \cdot \mathrm{m}^{-3}$ at $64 \mathrm{~d}$, OTC removal efficiency decreased temporarily but gradually recovered to the steady state at $97.2 \pm 1.6 \%$ from days 64 to 91 . The results indicated that microbes have been developed increasingly strong tetracycline resistance to overcome OTC bactericidal toxicity in long-term exposure of OTC, the domesticated desulphurizing bacteria in MBfR showed high tolerance to the OTC during the long-term operation.

Fig. 2(b) showed the performance of the integrated ozone-MBfR reactor for oxytetracycline removal during the 50-d continuous running test. OTC removal efficiency sharply fell, but gradually recovered to almost completely remove from days 3 to 10 after the supply of ozone concentration of $10 \mathrm{ppm}$. When ozone concentration was increased to $10 \mathrm{ppm}$ at $11 \mathrm{~d}$, OTC removal efficiency experienced an obvious fluctuation and could ascend to almost $100 \%$ at $20^{\text {th }} \mathrm{d}$. Maintained the OTC inlet concentration at a low 

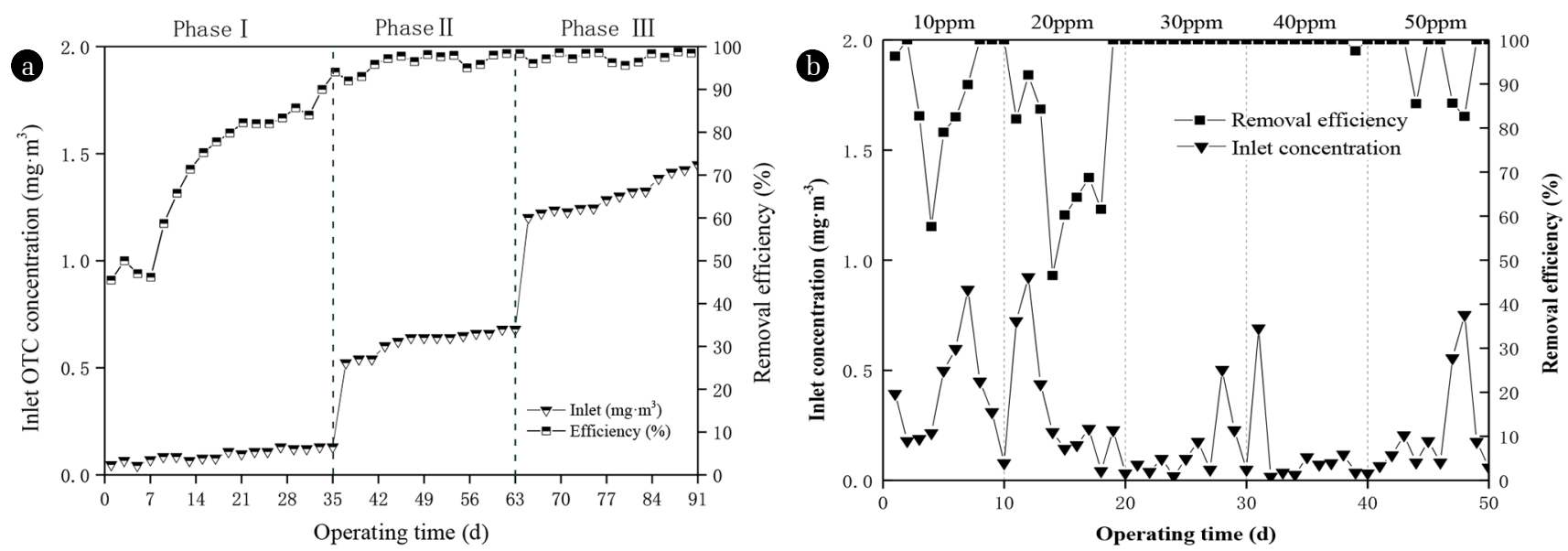

Fig. 2. Oxytetracycline removal performance of (a) MBfR and (b) ozone-MBfR.

concentration range of $0-0.2 \mathrm{mg} \cdot \mathrm{m}^{-3}$ from days 21 to 50 , when the ozone intake concentration was increased to $30 \mathrm{ppm}$, the OTC removal efficiency complete removal. When ozone inlet concentration was increased to $40 \mathrm{ppm}$, OTC was still completely removal. Until the ozone concentration rised to $50 \mathrm{ppm}$ at $43 \mathrm{~d}$, the OTC removal efficiency begined to decline and become less stable. This illustrated that ozone-MBfR had good OTC degradation performance under the conditions of ozone inlet concentration of 30-40 ppm, microorganisms in MBfR could efficiently adapt to the ozone, play a stable and efficient removal of OTC.

Pre-oxidation of ozone resulted in the formation of non-toxic degradation products, to improve the biodegradability and reduce OTC biotoxicity, microorganisms could more thoroughly degrade OTC and their primary products, eventually turn OTC into nitrates, $\mathrm{CO}_{2}$ and $\mathrm{H}_{2} \mathrm{O}$ [31]. Appropriate of ozone oxidation could also reduce OTC biotoxicity [32]. Thus, a bench scale system integrated with an ozone reactor and a membrane biofilm reactor unit should eliminate secondary pollution from decomposition of OTC by ozone process and more thoroughly degraded.

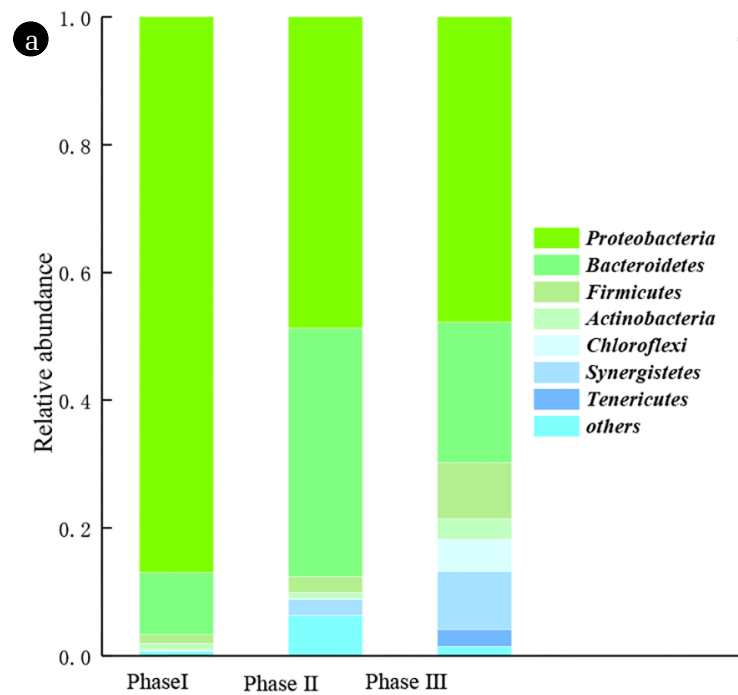

\subsection{Bacterial Community under OTC Stress}

As shown in Fig. 3(a), at the phylum level, Proteobacteria (47.786.9\%), Bacteroidetes (9.7-39.0\%), and Firmicutes (1.4-8.8\%) were dominant phylum in Phase I-III. Within the stress of OTC, Proteobacteria was the most abundant bacteria, which demonstrated that Proteobacteria was adapted to OTC stress and used OTC as carbon and energy sources, Firmicutes was of relatively high percentage of peptidoglycan of cytoderm, which was beneficial to generate resistance of OTC [33]. Some phyla, such as Firmicutes and Synergistetes, increased in abundance, whereas others, such as Proteobacteria, decreased.

At the genus level, OTUs in Phase I-III could be taxonomically classified into 375, 375 and 317, respectively. As shown in Fig. 3(b), the bacterial community was divided into three function groups, sulfur reducing bacteria (SRB), sulfur oxidizing bacteria (SOB), and fermentative bacteria (FB), their relative abundances were $19.5-36.2 \%, 19.3-38.4 \%$ and $22.0-29.6 \%$, respectively. With OTC concentration increasing from phase I to phaseII, the abundan-

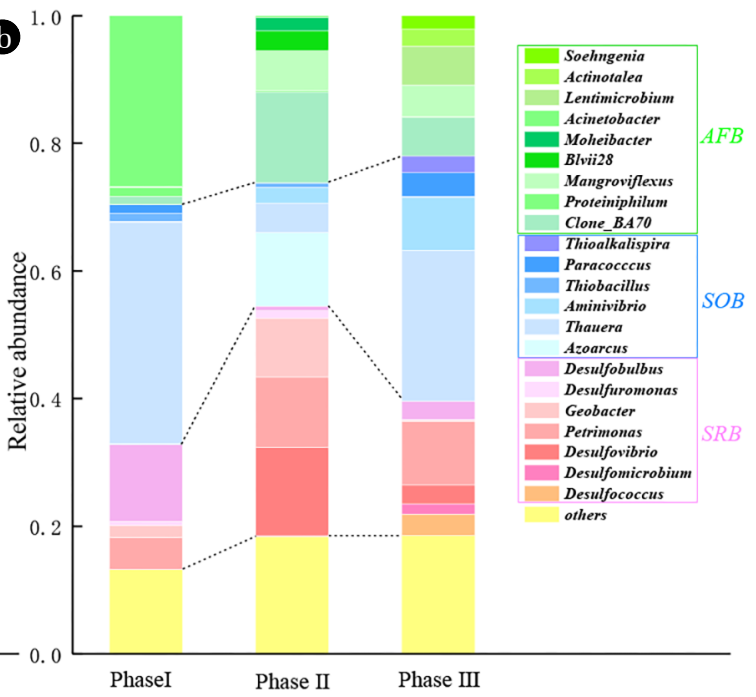

Fig. 3. Microbial community of MBfR at (a) phylum level, (b) at genus level under OTC stress. 
ces of SRB increased from $19.5 \%$ to $36.2 \%$, decreased to $21.1 \%$ in phase III, while the abundances of SOB decreased from $37.6 \%$ to $19.3 \%$, raised to $38.4 \%$ in phase III. The abundance of fermentative bacteria was decreased from phase I to phase III. Thauera may become progressively acclimatized to OTC feeding and act as the potential contributor to OTC biodegradation. Pseudomonas and Thiobacillus were certified to be antibiotics resistant bacteria which had good effectiveness in the biodegradation of antibiotics (OTC) [33]. Fermentative bacteria consumed carbon source to support energy and nutrient to DSB, such as Blvii28_wastewater-sludge_group and Mangroviflexus [34]. Moheibacter could resistant to OTC, and it was also biogenic sulfur oxidizing microbial consortia [35]. Comamonas, Sphingopyxis and Stenotrophomonas were resistant with antibiotics (OTC) [33], and Moheibacter, Comamonas, Pseudomonas and Thiobacillus, could degrade OTC [36]. These bacteria were contributed to the biodegradation of OTC in MBfR.

\subsection{Bacterial Community Shift under Ozone Stress}

The microbial community of biofilm in ozon -MBfR and MBfR was assessed by 16S rRNA. The filtered sequences from the biofilm samples 40127 (ozone-MBfR), and 50539(MBfR) were taxonomically assigned to 231, and 231 OTUs, respectively. As shown in Fig. 4, there were 17 phyla in ozone -MBfR. The relative abundances of dominant bacteria Proteobacteria, Tenericutes, Bacteroidetes and Firmicutes were $36.47,23.96,15.22$, and $12.39 \%$, respectively. Proteobacteria could withstand the double impact of ozone and OTC in the exhaust gas. At genus, the relative abundances of dominant genera Desulfovibrio, Lentimicrobium, Aminivibrio, Thioalkalispira, Erysipelothrix, Mangroviflexus, Azoarcus, Thauera, Geobacter, Paracoccus, and Dethiosulfatibacter were 0.11, 0.08, 0.06, $0.05,0.05,0.04,0.04,0.03,0.02,0.02$ and $0.02 \%$, respectively.

With the addition of ozone, the community diversity in MBfR increased. Some phyla (Fig. 5(a)), such as Tenericutes, increased in abundance, whereas others, such as Proteobacteria, and Bacteroidetes, decreased. At the level of genus (Fig. 5(b)), the dominant bacteria Thauera (23.8\%) and Petrimonas (10\%) in MBfR were changed into Tenericutes- uncultured (23.8\%) and Desulfovibrio (10.9\%) of in ozone-MBfR, there was little variation in abundances of Thioalkalispira, Erysipelothrix, Mangroviflexus, Lentimicrobium, Aminivibrio after adding ozone. Some genera, such as Tenericutesuncultured, and Desulfovibrio, increased in abundance, whereas others, such as Thauera, and Petrimonas, decreased.

\subsection{Genetic Foundation for OTC Resistance}

As shown in Fig.6, the relative abundances of tetracycline efflux $\operatorname{pump}(t e t R$, tet $A$, tet $C$, tet $G)$ related genes was the highest, followed by ribosomal protection protein (tet32, tet36, tetO, tet $W$, tetQ), enzy-

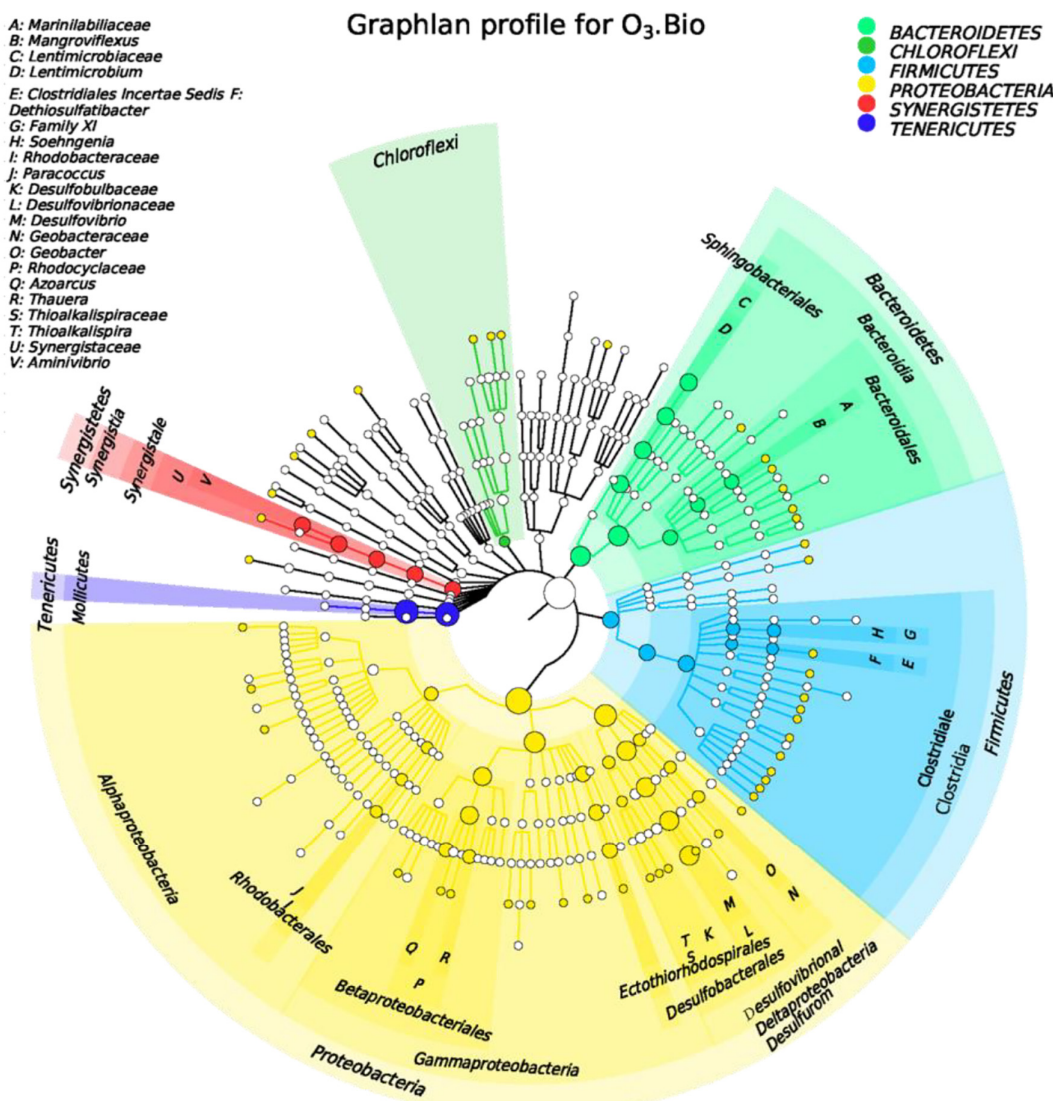

Fig. 4. Dominant bacteria at phylum, genus level in the ozone-MBfR. 

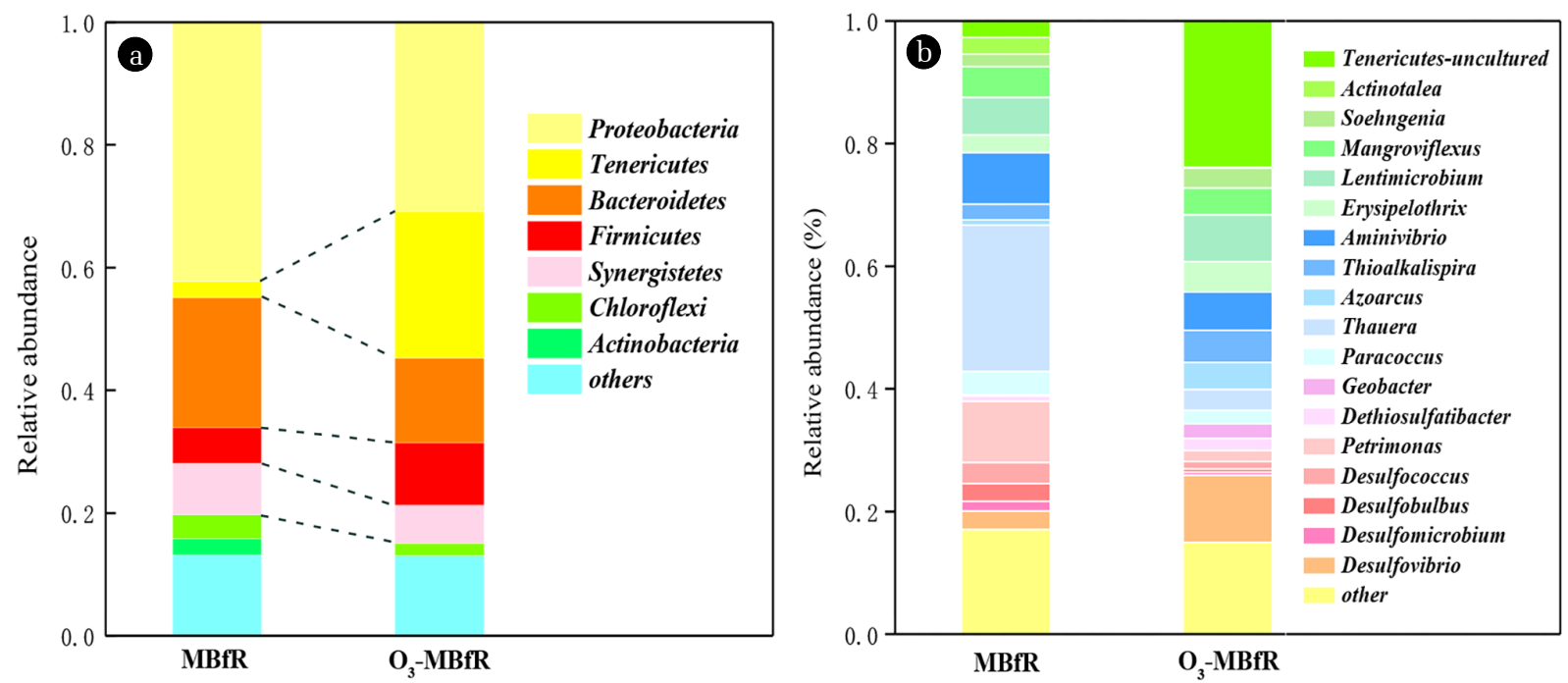

Fig. 5. Bacterial community in the MBfR and ozone $-M B f R$ (a) at phylum, (b) at genus.

matic modification protein ( $\operatorname{tet} X)$. The resistance proteins encoded by tetracycline resistance genes were categorized into four groups based on their function. Ribosomal protection protein protects ribosome from the translation inhibition of OTC [37]. Tetracycline efflux pump could reduce OTC concentration by using membrane transporter OTC to peripheral cytoplasm [38]. Enzymatic modification protein could inhibit OTC combination with tetracycline target via modifying tetracycline target and then inactivate OTC [39]. tet $X$ was identified as an NADH-dependent flavoprotein that performed OTC with hydroxylation dependent on oxygen. The enzyme encoded by tetX was able to transform both natural and semi-synthetic tetracyclines [40]. Tetracycline resistance proteins (K06962) may form polysaccharides on the cytomembrane to reduce the antibiotic into the cell [33].

Pseudomonas with tetG and tetR occupied highest ratio (38.45\%)

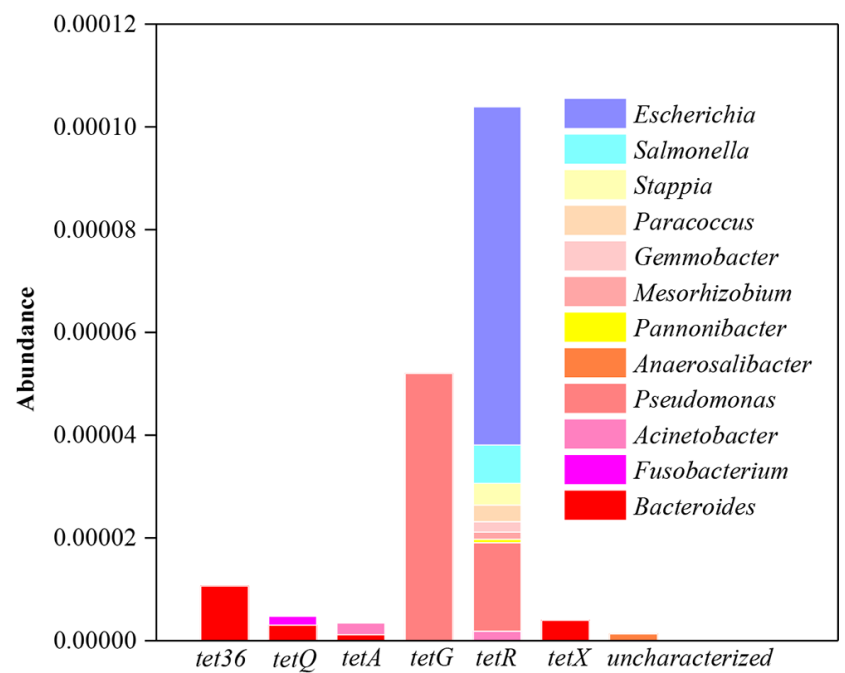

Fig. 6. Metagenome functional genes assigned to tetracycline resistance and functional contribution of bacterial genera. in OTC resistant bacteria followed by Escherichia (36.57\%). The antibiotics resistant bacteria (ARB) were mainly represented by taxa with genes tetG, tet $G$, such as Pseudomonas, Escherichia, Bacteroides, Paracoccus, Stappia and etc. Pseudomonas could effectively degrade OTC [36]. Bacteroides could degrade macromolecules effectively [40] and could transform tetracycline [41]. Therefore, these bacteria were responsible for OTC metabolism.

\subsection{OTC Degradation Products}

In MBfR without ozone, the intermediate products from OTC biodegradation such as $\mathrm{C}_{22} \mathrm{H}_{20} \mathrm{~N}_{2} \mathrm{O}_{8}(\mathrm{~m} / \mathrm{z}=443), \mathrm{C}_{20} \mathrm{H}_{18} \mathrm{~N}_{2} \mathrm{O}_{8}(\mathrm{~m} / \mathrm{z}=$ 415), $\mathrm{C}_{20} \mathrm{H}_{15} \mathrm{NO}_{3}(\mathrm{~m} / \mathrm{z}=318), \mathrm{C}_{18} \mathrm{H}_{16} \mathrm{O}_{5}(\mathrm{~m} / \mathrm{z}=313), \mathrm{C}_{20} \mathrm{H}_{15} \mathrm{NO}_{2}$ $(\mathrm{m} / \mathrm{z}=302), \mathrm{C}_{11} \mathrm{H}_{13} \mathrm{NO}_{2}(\mathrm{~m} / \mathrm{z}=192)$ and $\mathrm{C}_{10} \mathrm{H}_{12} \mathrm{O}(\mathrm{m} / \mathrm{z}=149)$ were detected by LC-TOF-MS/MS. The intermediate products from OTC ozone oxidation such as $\mathrm{C}_{22} \mathrm{H}_{24} \mathrm{~N}_{2} \mathrm{O}_{10} \quad(\mathrm{~m} / \mathrm{z}=477)$, $\mathrm{C}_{22} \mathrm{H}_{24} \mathrm{~N}_{2} \mathrm{O}_{9}(\mathrm{~m} / \mathrm{z}=461), \mathrm{C}_{22} \mathrm{H}_{20} \mathrm{NO}_{8}(\mathrm{~m} / \mathrm{z}=426)$ and $\mathrm{C}_{21} \mathrm{H}_{18} \mathrm{NO}_{8}(\mathrm{~m} / \mathrm{z}$ $=412$ ) were detected in the sample after ozone reaction. In the ozone-MBfR, the intermediate products from OTC degradation such as $\mathrm{m} / \mathrm{z}=274, \mathrm{~m} / \mathrm{z}=246, \mathrm{~m} / \mathrm{z}=218, \mathrm{~m} / \mathrm{z}=192, \mathrm{~m} / \mathrm{z}=179$, $\mathrm{m} / \mathrm{z}=149, \mathrm{~m} / \mathrm{z}=113$ and $\mathrm{m} / \mathrm{z}=81$ were detected in the sample after ozone-biodegradation. The minimum intermediate molecular weight product detected in MBfR only was $\mathrm{C}_{10} \mathrm{H}_{12} \mathrm{O}(\mathrm{m} / \mathrm{z}=149)$ with two ring structures. The smallest product detected in ozone-MBfR was $\mathrm{C}_{6} \mathrm{H}_{8}(\mathrm{~m} / \mathrm{z}=81)$ with a chain-like structure. By comparing the intermediate products detected in MBfR and ozone-MBfR, it could be seen that ozone-biodegration could degrade OTC more thoroughly.

\subsection{Mechanistic Insights of Zone-Biodegradation of OTC}

Proposed OTC degradation pathways for ozone-MBfR integrated reactor were shown in Fig. 7. Ozone could degrade OTC into intermediate products, these intermediate products and OTC were oxidized to nitrate, carbon dioxide, water by biological degradation. In the OTC ozone oxidation process, the C11a-C12 double bond of OTC underwent 1, 3-dipole ring addition reaction by ozone, adding oxygen to generate $\mathrm{C}_{22} \mathrm{H}_{24} \mathrm{~N}_{2} \mathrm{O}_{10}(\mathrm{~m} / \mathrm{z}=477)$ [42]; dehydration 


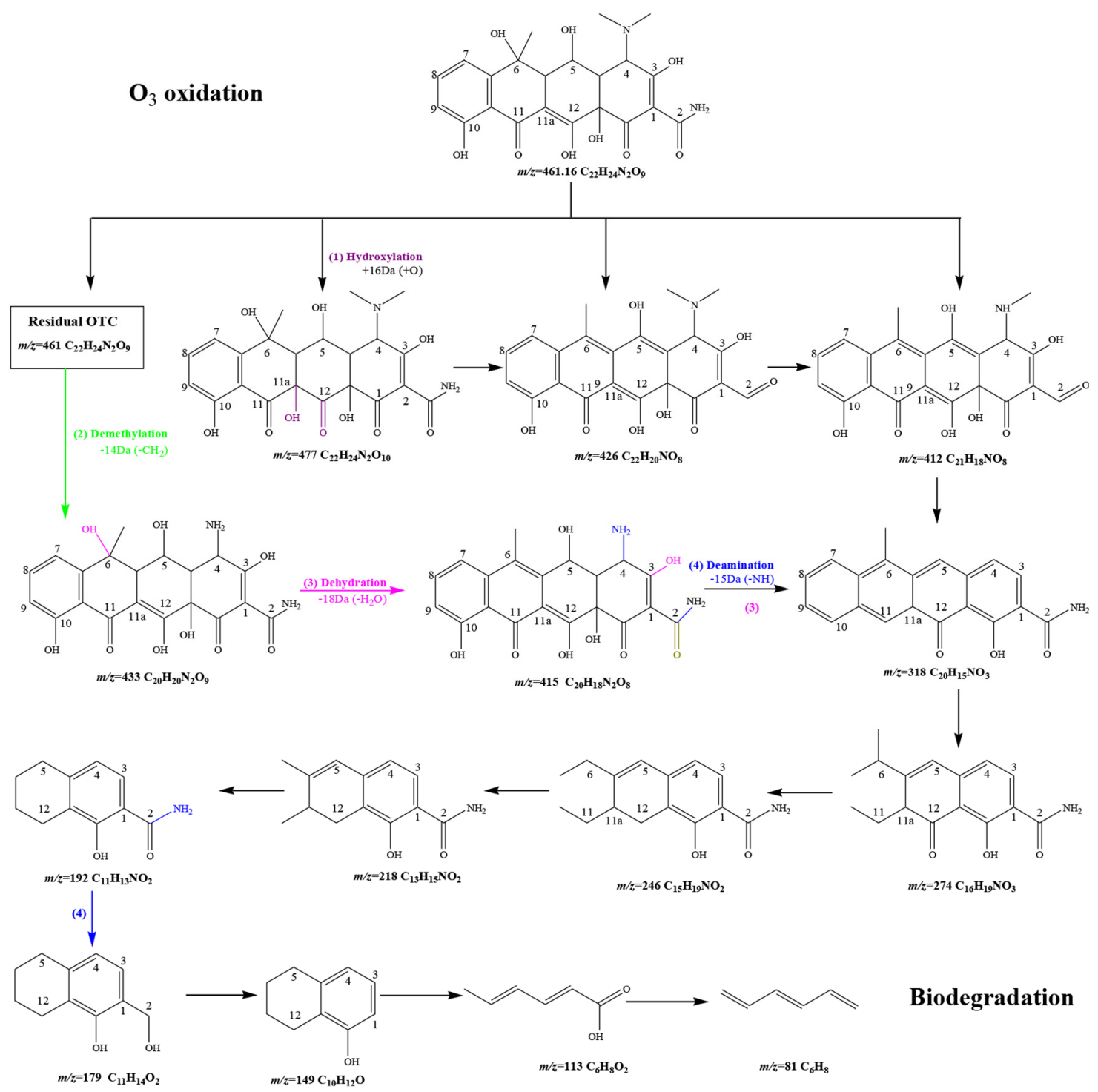

Fig. 7. Proposed degradation pathways of oxytetracycline in the ozone-MBfR.

of C6, deamination of $\mathrm{C} 2$, and secondary alcohol oxidation of C5 of OTC produced $\mathrm{C}_{22} \mathrm{H}_{20} \mathrm{NO}_{8}(\mathrm{~m} / \mathrm{z}=426)$, to further get $\mathrm{C}_{21} \mathrm{H}_{18} \mathrm{NO}_{8}$ $(\mathrm{m} / \mathrm{z}=412)$ after demethylation of C4 of OTC. In the OTC biodegradation process, the intermediate products from OTC ozone oxidation and OTC were further degraded by microorganisms. OTC was demethylated to produce $\mathrm{C}_{20} \mathrm{H}_{20} \mathrm{~N}_{2} \mathrm{O}_{9}(\mathrm{~m} / \mathrm{z}=433)$ [43], to get $\mathrm{C}_{20} \mathrm{H}_{15} \mathrm{NO}_{3}(\mathrm{~m} / \mathrm{z}=318)$ after deamination and dehydration. When $\mathrm{C}$ and D rings of OTC were cleaved, and after decarbonization and deoxidation, the product $\mathrm{M} / \mathrm{Z}=274$ was generated. The $\mathrm{C}$ ring of OTC was decomposed gradually, to prodce $\mathrm{C}_{15} \mathrm{H}_{19} \mathrm{NO}_{2}(\mathrm{~m} / \mathrm{z}$ $=246), \mathrm{C}_{13} \mathrm{H}_{15} \mathrm{NO}_{2}(\mathrm{~m} / \mathrm{z}=218)$ and $\mathrm{C}_{11} \mathrm{H}_{13} \mathrm{NO}_{2}(\mathrm{~m} / \mathrm{z}=192)$ successively. The amide group of $\mathrm{C}_{11} \mathrm{H}_{13} \mathrm{NO}_{2}(\mathrm{~m} / \mathrm{z}=192)$ was cleaved, resulting in the products $(\mathrm{m} / \mathrm{z}=179)$ and $\mathrm{C}_{10} \mathrm{H}_{12} \mathrm{O}(\mathrm{m} / \mathrm{z}$ $=149$ ). These products were further metabolized into sorbic acid $(\mathrm{m} / \mathrm{z}=113)$ [44]. Sorbic acid was stripped of its hydroxyl radical and oxygen atoms to chain-like structure $\mathrm{C}_{6} \mathrm{H}_{8}(\mathrm{~m} / \mathrm{z}=81)$, which was eventually degraded to $\mathrm{CO}_{2}$ and $\mathrm{H}_{2} \mathrm{O}$. Thus, ozone oxidation could degrade OTC into readily biodegradable substances with low biotoxicity, the products and OTC were biodegraded to nitrate, carbon dioxide, and water. Ozone was combined with MBfR biodegradation could achieved compeletely removal of OTC in waste gas.

\subsection{Environmental Implication and Engineering Application}

Resource recovery of solid waste refers to the comprehensive utilization of solid waste to make it available as secondary resources, such as biomass resources into hydrogen production, biodiesel [45, 46], Kaolin-clay into Kaolin-jute fibers filters [47], sludge disposal [48], agricultural solid waste composting into organic fertilizer to diminish the challenges to the global environment. The recycling process of compost will produce odor waste gas. Biological processes have become the mainstream technology for malodorous waste 
gases treatment.

Compared with the intermediate products of OTC degradation by ozone oxidation and biodegradation, ozone oxidation had insufficient degradation on OTC, and microorganism could not degrade OTC more thoroughly and produce intermediates. Therefore, the combination of ozone oxidation and MBfR achieved complete removal of OTC in exhaust gas. This provides a new way of GEOCs treatment using the novel hybrid ozone and membrane biofilm reactor, serves the purpose to build emerging organic pollutant emission control strategy based on ozone-MBfR, has scientific basis for potential application value.

\section{Conclusions}

The paper revealed that the integrated with ozone and membrane biofilm reactor could thoroughly degrade OTC in waste gas. The dominant genera include Desulfovibrio, Lentimicrobium, Aminivibrio, Thioalkalispira, Erysipelothrix, Mangroviflexus, Azoarcus, Thauera, Geobacter, Paracoccus, and Dethiosulfatibacter. Eleven tetracycline resistance genes, including tet32, tet36, tet $O$, tet $W$, and tetQ, tet $A$, tet $C$, tet $G$, tet $X$, tetR; dimethylamine and amidogroup metabolic genes $d m d, q h p A, f d h A$ and formamidase existed in a membrane bioreactor. With the addition of ozone, some genera, such as Tenericutes- uncultured, and Desulfovibrio, increased in abundance, whereas others, such as Thauera, and Petrimonas, decreased. The OTC degradation mechanism of ozone-MBfR was that pre-oxidation of ozone could destroy the enol structure and produce easily biodegradable products, those products were further biodegradation to inorganic matter. Pre-oxidation of ozone help to degrade gaseous OTC more thoroughly.

\section{Acknowledgments}

The authors gratefully acknowledge the financial support from the Guangdong Basic and Applied Basic Research Foundation (2019B1515120021) and Guangdong Science \&Technology Project (2019B11021003).

\section{Author Contributions}

X.L.C. (M.S. student) takes charge of investigation, scientific experiments, data curation, formal analysis and writing; Z.S.W. (Professor) provided supervision, theoretical foundation, and experimental guidance; Z.S.H. (Ph.D. student) takes charge of manuscript reviewing \& editing; H.Y.J. (M.S. student) assisted in conducting experiments and computational analysis; X.L.X. (Ph.D. student) is responsible for in literature researches.

\section{References}

1. Yin C, Qiu SX, Zhang SF, et al. Strength degradation mechanism of iron coke prepared by mixed coal and $\mathrm{Fe}_{2} \mathrm{O}_{3}$. J. Anal. Appl.
Pyrolysis 2020;150:104897.

2. Başer B, Yousaf B, Yetis U, et al. Formation of nitrogen functionalities in biochar materials and their role in the mitigation of hazardous emerging organic pollutants from wastewater. J. Hazard. Mater. 2021;416:126131.

3. Smrmah AK, Meyer MT, Boxall ABA. A global perspective on the use, sales, exposure pathways, occurrence, fate and effects of veterinary antibiotics (VAs) in the environment. Chemosphere 2006;65:725-759.

4. Zhang M, He L, Liu Y, et al. Fate of veterinary antibiotics during animal manure composting. Sci. Total Environ. 2019;650:1363-1370.

5. Yu Y, Chen L, Fang Y, et al. High temperatures can effectively degrade residual tetracyclines in chicken manure through composting. J. Hazard. Mater. 2019;380:120862.

6. Zheng F, An XL, Zhou GW, et al. Mite gut microbiome and resistome exhibited species-specific and dose-dependent effect in response to oxytetracycline exposure. Sci. Total Environ. 2021;807:150802.

7. Liao H, Lu X, Rensing C, et al. Hyperthermophilic composting accelerates the removal of antibiotic resistance genes and mobile genetic elements in sewage sludge. Environ. Sci. Technol. 2017;52:266-276.

8. Wang B, ZhaoYY, Lan ZH, et al. Sampling methods of emerging organic contaminants in indoor air. Trends Environ. Anal. Chem. 2016;12:13-22.

9. Wu XF, Wei YS, Zheng JX, et al. The behavior of tetracyclines and their degradation products during swine manure composting. Bioresour. Technol. 2011;102:5924-5931.

10. Wu X, Wei Y, Zheng J, et al. The behavior of tetracyclines and their degradation products during swine manure composting. Bioresour. Technol. 2011;102:5924-5931.

11. Mbareche H, Veillette M, Bonifait L, et al. A next generation sequencing approach with a suitable bioinformatics workflow to study fungal diversity in bioaerosols released from two different types of composting plants. Sci. Total Environ. 2017;601602:1306-1314.

12. Qi YF, Wu SQ, Xi F, et al. Performance of a coupled micro-electrolysis, anaerobic and aerobic system for oxytetracycline (OTC) production wastewater treatment. J. Chem. Technol. Biotechnol. 2016;91:1290-1298.

13. Sun Y, Wang XJ, Xia SQ, et al. New insights into oxytetracycline (OTC) adsorption behavior on polylactic acid microplastics undergoing microbial adhesion and degradation. Chem. Eng. J. 2021;416:129085.

14. Ahmeda MB, Zhoua J, Ngoa HH, et al. Progress in the biological and chemical treatment technologies for emerging contaminant removal from wastewater:A critical review. J. Hazard. Mater. 2017;323:274-298.

15. Çelik A, Casey E, Hasar H. Degradation of oxytetracycline under autotrophic nitrifying conditions in a membrane aerated biofilm reactor and community fingerprinting. J. Hazard. Mater. 2018;356:26-33.

16. Harrabi M, Alexandrino DAM, Aloulou F. Biodegradation of oxytetracycline and enrofloxacin by autochthonous microbial communities from estuarine sediments. Sci. Total Environ. 2019;648:962-972. 
17. Fang YD, Vanzin G, Cupples AM, et al. Influence of terminal electron-accepting conditions on the soil microbial community and degradation of organic contaminants of emerging concern. Sci. Total Environ. 2020;706:135327.

18. Patel M, Kumar R, Kishor K, et al. Pharmaceuticals of emerging concern in aquatic systems:chemistry, occurrence, effects, and removal methods. Chem. Rev. 2019;119:3510-3673.

19. Zhang QQ, Qian H. Insight into the evolution of microbial community and antibiotic resistance genes in anammox process induced by copper after recovery from oxytetracycline stress. Bioresour. Technol. 2021;330:124945.

20. Li SJ, Shi XS, Lu MY, et al. Accelerated adsorption of tetracyclines and microbes with $\mathrm{FeOn}(\mathrm{OH}) \mathrm{m}$ modified oyster shell:Its application on biotransformation of oxytetracycline in anaerobic enrichment culture. Chem. Eng. J. 2021;425:130499.

21. Li KX, Yediler A, Yang M, et al. Ozonation of oxytetracycline and toxicological assessment of its oxidation by-products. Chemosphere 2008;72:473-478.

22. Uslu MO, Balcioglu IA.Ozonation of animal wastes containing oxytetracycline. Ozone Sci. Eng.2008;4:290-299.

23. Wang Y, Zhang H, Zhang JH, et al. Degradation of tetracycline in aqueous media by ozonation in an internal loop-lift reactor. J. Hazard. Mater. 2011;192:35-43.

24. Feng MB, Yan LQ, Zhang XL, et al. Fast removal of the antibiotic flumequine from aqueous solution by ozonation:Influencing factors, reaction pathways, and toxicity evaluation. Sci. Total Environ. 2016;541:167-175.

25. Cai MJ, Lin YP. Effects of effluent organic matter (EfOM) on the removal of emerging contaminants by ozonation. Chemosphere 2016;151:332-338.

26. Guo Y, Zhao EZ, Wang J, et al. Comparison of emerging contaminant abatement by conventional ozonation, catalytic ozonation, $\mathrm{O}_{3} / \mathrm{H}_{2} \mathrm{O}_{2}$ and electro-peroxone processes. J. Hazard. Mater. 2019;389:121829.

27. Rodriguez-Narvaez OM, Peralta-Hernandez JM, Goonetilleke A, et al. Treatment technologies for emerging contaminants in water:A review. Chem. Eng. J. 2017;323:361-380.

28. Ralebitso-Senior TK, Senior E, Felice RD, et al. Waste gas biofiltration:advances and limitations of current approaches in microbiology. Environ. Sci. Technol. 2012;46:8542-8573.

29. Escher RB, Macova M, Argaud F, et al. Ozonation and biological activated carbon filtration of wastewater treatment plant effluents. Water Res. 2012;46:863-872.

30. Lee CO, Howe KJ, Thomson BM. Ozone and biofiltration as an alternative to reverse osmosis for removing PPCPs and micropollutants from treated wastewater. Water Res. 2012;46: 1005-1014.

31. Fauque G, Peck HD, Moura JJG, et al. The three classes of hydrogenases from sulfate-reducing bacteria of the genus Desulfovibrio. FEMS Microbiol. Rev. 1988;54:299-344.

32. Doi AM, Stoskopf MK. The Kinetics of Oxytetracycline Degradation in Deionized Water under Varying Temperature, pH, Light, Substrate, and Organic Matter. J. Aquat. Anim. Health 2000;12:246-253.

33. Chen J, Yang Y, Liu Y, et al. Bacterial community shift and antibiotics resistant genes analysis in response to biodegradation of oxytetracycline in dual graphene modified bioelectrode microbial fuel cell. Bioresour. Technol. 2019;276:236-243.

34. Baldwin SA, Khoshnoodi M, Rezadehbashi M, et al. The microbial community of a passive biochemical reactor treating arsenic, zinc, and sulfate-rich seepage. Front. Bioeng. Biotechnol. 2015;3:1-13

35. Kostrytsia A, Papirio S, Morrison L, et al. Biokinetics of microbial consortia using biogenic sulfur as a novel electron donor for sustainable denitrification. Bioresour. Technol. 2018;270:359-367.

36. Qi WN, Long J, Feng CQ, et al. $\mathrm{Fe}^{3+}$ enhanced degradation of oxytetracycline in water by pseudomonas. Water Res. 2019;160:361-370.

37. Zahid S, Bin-Asif H, AliHasan K, et al. Prevalence and genetic profiling of tetracycline resistance (Tet-R) genes and transposable element (Tn916) in environmental enterococcus species. Microb. Pathogenesis 2017;111:252-261.

38. Li C, Lu JJ, Liu J, et al. Exploring the correlations between antibiotics and antibiotic resistance genes in the wastewater treatment plants of hospitals in Xinjiang, China. Environ. Sci. Pollut. Res. 2016;23:15111-15121.

39. Shi ZJ, Hu HY, Shen YY, et al. Long-term effects of oxytetracycline (OTC) on the granule-based anammox:Process performance and occurrence of antibiotic resistance genes. Biochem. Eng. J. 2017;127:110-118.

40. Xia D, Yi XY, Lu Y, et al. Dissimilatory iron and sulfate reduction by native microbial communities using lactate and citrate as carbon sources and electron donors. Ecotoxicol. Environ. Saf. 2019;174:524-531.

41. Reis AC, Kolvenbach BA, Nunes OC, et al. Biodegradation of antibiotics-The new resistance determinants-part I. New Biotechnol. 2020;54:34-51.

42. Dalmázio I, Almeida MO, Augusti R, et al. Monitoring the degradation of tetracycline by ozone in aqueous medium via atmospheric pressure ionization mass spectrometry. J. Am. Soc. Mass. Spectrom. 2007;18:679-687.

43. Li ZJ, Qi WN, Liu YW, et al. Degradation mechanisms of oxytetracycline in the environment. J. Integr. Agr. 2019;18:1953-1960.

44. Ding R, Yan WF, Wu Y, et al. Light-excited photoelectrons coupled with bio-photocatalysis enhanced the degradation efficiency of oxytetracycline. Water Res. 2018;143:589-598.

45. Azizan MT, Aqsha A, Ameen M, et al. Catalytic reforming of oxygenated hydrocarbons for the hydrogen production: an outlook. Biomass Conv. Bioref. 2020;1-24.

46. Nazir MH, Ayoub M, Zahid I, et al. Waste sugarcane bagasse-derived nanocatalyst for microwave-assisted transesterification:Thermal, kinetic and optimization study. Biofuels Bioprod. Bioref. 2021;2264.

47. Hussain TS, Al-Fatlawi AH. Remove chemical contaminants from potable water by household water treatment system. Civil Eng. J. 2020;6:1534-1546.

48. Ali Bhatti ZA, Qureshi K, Maitlo G, et al. Study of PAN Fiber and Iron ore Adsorbents for Arsenic Removal. Civil Eng. J. 2020;6:548-562. 